\title{
Kronik Obstruktif Akciğer Hastalığı Olan Bireylerde Uyku Kalitesi ile Anksiyete ve Depresyon Arasındaki Ilişki
}

\author{
Gül Dural@, Seyhan Çıtlık Sarıtaş®
}

İnönü Üniversitesi, Hemşirelik

Fakültesi, İç Hastalıkları Hemşireliği

Anablim Dalı, Malatya, Türkiye

Gül Dural, Arş. Gör.

Seyhan Çıtlık Sarıtaş, Dr. Öğr. Üyesi

Iletişim:

Arş. Gör. Gül Dural

İnönü Üniversitesi, Hemşirelik Fakültesi, ļ̇ Hastalıkları Hemşireliği Anablim Dalı, Malatya, Türkiye

Tel: +90 4223411338

E-Posta: gulkaya2224@gmail.com

\section{ÖZET}

Amaç: Kronik Obstrüktif Akciğer Hastalığı (KOAH)'nda, hastalar yoğun yaşadıkları nefes darlığı gibi semptomlar nedeni ile uykularını yeterli alamamakta, uyku kalitesi olumsuz etkilenmekte, anksiyete ve depresyon yaşayabilmektedir. Bu çalışma KOAH olan bireylerde uyku kalitesi ile anksiyete ve depresyon arasındaki ilişkinin belirlenmesi amacıyla yapııııı̧tır.

Yöntem: Tanımlayıı tipteki bu çalışma; gönüllï olan, iletişime açık, 144 KOAH hastası ile yapıldı. Çalışma verilerinin toplanmasında hastaların tanıtıı özelliklerini içeren "Veri Toplama Formu", , Pittsburgh Uyku Kalitesi İndeksi (PUKi)" ve "Hastane Anksiyete ve Depresyon Ölçeği (HAD)" kullanılmıştır. Çalışmanın verileri 0cak 2016-Nisan 2016 tarihlerinde hastalara açıklama yapıldıktan sonra anket formunun uygulanması ile toplanmıştır. Verilerin değerlendirilmesinde sayı, yüzde, ortalama, bağımsız gruplarda t-testi, pearson korelasyon analiz kullanıımı̧tır.

Bulgular: Çalışma kapsamına alınan hastaların \%59.7'sinin erkek, \%84.7'sinin 55 yaş ve üstü, \%88.2'sinin evli, \%51.4'ünün ilköğ-

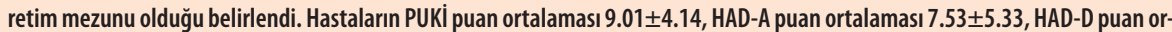
talaması $10.27 \pm 5.31$ ve HAD-Toplam puan ortalaması $17.79 \pm 9.59$ olarak bulunmuştur. Araştırmaya katılan hastaların \%77.8'inin kötü uyku kalitesine sahip olduğu, $\% 75^{\prime}$ inin anksiyetesinin olmadığı ve \%68.7'inin depresyonu olduğu belirlendi. Uyku kalitesi ile anksiyete ve depresyon arasında anlamlı ilişki olduğu saptanmıştır $(p<0.01)$. Hastaların uyku kaliteleri düşerken, anksiyete ve depresyon düzeylerinin arttığı görülmüştür.

Sonuç: KOAH hastalarının düşük uyku kalitesine sahip olduğu ve çoğunun depresyon yaşadığı saptandı. Hastaların uyku kalitelerinin düştükçe anksiyete ve depresyonlarının arttığı görüldü. Bu durumda hastalara destekleyici bir psikolojik yardım ile uygun farmakolojik yöntemlerin kullanııldı̆ı bir yaklaşım gerekmektedir. Bu konuda eğitim almış hemşirelerin KOAH hastalarına ve yakınlarına uygun eğitim programları düzenlenmesi önerilebilir.

Anahtar sözcükler: Anksiyete, depresyon, hemşirelik, KOAH, uyku kalitesi

THE RELATIONSHIP BETWEEN SLEEP QUALITY, ANXIETY AND DEPRESSION IN PATIENTS WITH CHRONIC OBSTRUCTIVE PULMONARY DISEASE

\section{ABSTRACT}

Objectives: In patients with Chronic Obstructive Pulmonary Disease (COPD), patients may experience inadequate sleep due to symptoms such as shortness of breath. Patients may have poor sleep quality and experience anxiety and depression.

Study design: In this descriptive study, voluntary, open communication, 144 COPD patients were included. 'Data Collection Form', 'Pittsburgh Sleep Quality Index (PUKI)' and 'Hospital Anxiety and Depression Scale (HADS)' were used in the collection of study data. The data for the study were collected from January 2016 to April 2016. Numbers, percentages, mean, independent t-test, pearson correlation analysis were used in the evaluation of the data.

Results: It was determined that $59.7 \%$ of the patients included in the study were male, $84.7 \%$ were 55 years and over, $88.2 \%$ were married. Mean PUKI score was $9.01 \pm 4.14$, mean HAD-A score was $7.53 \pm 5.33$, mean HAD-D score was $10.27 \pm 5.31$ and mean HAD-total score was $17.79 \pm 9.59$. It was determined that $77.8 \%$ of the patients participating in the study had poor sleep quality, $75 \%$ had no anxiety and $68.7 \%$ had depression. There was a significant relationship between sleep quality and anxiety and depression $(\mathrm{p}<0.01)$. As the sleep quality of patients decreased, anxiety and depression levels increased.

Conclusion: Patients with COPD were found to have low sleep quality and were mostly depressed. Anxiety and depression increased when sleep quality of the patients decreased. In this case, an approach using a pharmacologic approach with diseasesupporting psychological help is required. Nurses trained in this area may be advised to arrange appropriate training programs for COPD patients and their relatives.

Keywords: Anxiety, COPD, depression, nursing, sleep quality.
Gönderilme Tarihi : 15 Eylül 2017

Revizyon Tarihi : 05 Ekim 2017

Kabul Tarihi : 15 Ekim 2017 
K ronik Obstruktif Akciğer Hastalığı (KOAH), dünyadaki morbidite ve mortalite nedenleri arasında ilk sıralardadır. 2020 yılında ölüm nedenleri içinde üçüncü sırada olacağı beklenmektedir (1-4). Dünyada 600 milyondan fazla, ülkemizde ise 2-3 milyon $\mathrm{KOAH}$ hastası vardır (5). KOAH kronik bronşit ve amfizemi kapsayan, dispne, öksürük ve balgam çıkarma gibi semptomlarla ilişkili bir hastalıktır (6-10). Ilerleyici ancak aynı zamanda önlenebilir ve tedavi edilebilir bir hastalıktır $(6,11)$.

$\mathrm{KOAH}$, bireylerin fiziksel, sosyal ve duygusal durumlarını ciddi şekilde etkiler $(2,3,12)$. Bazen bireylerin beyin fonksiyonlarını etkileyerek psikiyatrik rahatsızlıklara yola açabilir. Bazen de bireylerin yaşam şekillerine etkide bulunarak psikiyatrik sorunların ortaya çıkmasına neden olabilir (3). Aynı zamanda hastalardaki solunum işlevinde düşme ve hastalığın neden olduğu semptomlar nedeniyle periferik kas zayıflı̆̆ı, egzersiz toleransında azalma, yaşam kalitesinde azalma, depresyon ve anksiyete gibi problemler yaşanabilmektedir (13). Anksiyete ve depresyon KOAH'da sıklıkla görülen psikiyatrik problemlerdendir. Anksiyete depresyondan daha önce görülür $(4,14)$. Depresyon genellikle geç fark edilmektedir (3). Anksiyetenin derecesi KOAH'ın ve hastalardaki işlev bozukluğunun şiddetine bağlıdır. Hem anksiyete hem de depresyon KOAH'ın prognozunu etkiler. Ne yazık ki bu durumlar KOAH hastaları için yeterince değerlendirilmemektedir (4). Anksiyete, hastalardaki dispne gibi fiziksel semptomları etkileyebilmektedir (14). KOAH'da anksiyetenin öz yeterlik, öz bakım, $\mathrm{KOAH}$ alevlenmeleri ve mortalite açısından olumsuz etkileri olduğu görülmüştür. Yüksek anksiyete ve depresyon düzeyinin KOAH hastalarında semptom yönetimini olumsuz etkileyerek öz bakımı azaltmaktadır (15). Yapılan bir çalışmada duygusal yönden sıkıntılı olan kadın KOAH'ı hastaların mortalite oranlarının daha yüksek olduğu görülmüştür (16). KOAH'da anksiyete ve depresyon göz ardı edilmemelidir (17).

Uyku kalitesi, KOAH'ı olan birçok hastada belirgin olarak tehlikeye girer ve bazı komorbiditeler mevcut olduğunda daha da kötüleşebilir (6). Parçalanmış uyku ve sık uyanışlar vardır. Bunlar da hastaların gündüz uyumalarına neden olur (18). KOAH'da dispne ve halsizlikten sonra en fazla görülen semptom uyku bölünmesidir. Hastaların \%34-50'sinin uyku bozuklukları ve gece uyanmaları yaşadıkları görülmüştür $(19,20)$. Hastalarda insomnia, kabus görme ve gündüz aşırı uyku hali sağlıklı bireylere göre daha fazla görülmektedir (20). Özellikle ilerleyen evrelerde uyku bozuklukları görülme sıklığı artar (21). Azalan uyku kalitesi yorulma, psikiyatrik problemler ve yaşam kalitesinin bozulması ile ilişkilidir (6). Uyku kalitesinin düşmesi var olan hipoksemi ve hiperkapniyi kötüleştirebilmektedir (14). Hastalarda gündüzleri azalmış olan kas kontraktilitesi uykudayken daha fazla azalır, diyafram fonksiyonu bozulabilir. Bunun sonucu olarak hastaların dakikadaki ventilasyonlarında sağlıklı bireylere göre belirgin azalma görülür. Bunların sonucu olarak hastalarda uykudayken gaz alışverişinde ciddi bozulmalar görülebilmekte ve ciddi hipoksemi ve hiperkapni görülebilmektedir (19). Uyku bozuklukları hastaların yaşam kalitelerinin düşmesini ve hastalık yükünün artmasına neden olmaktadır (14).

KOAH'ın dünya ve ülkemiz için önemli bir sağlık problemi olduğu, hastaların sosyal, mental ve fiziksel işlevselliklerini önemli derecede etkilediği bilinmektedir. KOAH hastaların da anksiyete ve depresyon ile uyku bozuklukları görülebilmektedir. Bunlar hastalığın prognozunu olumsuz etkilemektedir. Hastaların işlevselliklerini etkileyen uyku kalitesi ile anksiyete ve depresyon arasındaki ilişki bilinirse daha etkili bakım ve tedavi programlarının oluşturulabileceği düşünülmektedir. Aynı zamanda bu araştırmanın sonuçlarının, başka çalışmalara temel oluşturması ve hemşirelik bilimine katkı sağlaması düşünülmektedir. Bu konuda yapılan çalışmalara rastlanmamış olması nedeniyle bu çalışmanın yapılmasına karar verildi. Bu çalışma kronik obstruktif akciğer hastalarında anksiyete ve depresyonun uyku kalitesi ile ilişkisini belirlemek amacıyla yapıldı. Bu çalışmada araştırma soruları şunlardır:

- KOAH hastalarında anksiyete ve depresyon düzeyi ne kadardır?

- KOAH hastalarında uyku kalitesi nasıldır?

- KOAH hastalarında anksiyete ve depresyon ile uyku kalitesi arasında ilişki var mıdır?

\section{Gereç ve yöntemler}

Araştırma tanımlayıcı ilişkisel tipte yapıldı. Araştırmanın evrenini bir Üniversite Hastanesinin Göğüs Hastalıkları servisinde yatmakta olan KOAH tanısı konmuş hastalar oluşturdu. Örneklem seçiminde herhangi bir örnekleme yöntemi kullanılmadan, araştırma kriterlerine uyan ve araştırmaya katılmaya gönüllü olan 144 hasta örneklem grubuna dahil edildi. Araştırma verileri Ocak 2016-Nisan 2016 tarihleri arasında toplandı. Araştırma kapsamına okur-yazar olan, iletişime açık, çalışmaya katılmaya gönüllü olan bireyler alındı. Araştırma verileri, araştırmacı tarafından hasta odalarında sessiz bir ortam sağlanarak yüz yüze görüşme yöntemiyle toplandı. Her bir hasta ile görüşme yaklaşık 10-15 dakika sürdü 
Araştırmada veri toplama aracı olarak; katılımcıların sosyo-demografik özelliklerini içeren hasta tanıtım formu, Pittspurg Uyku Kalitesi İndeksi (PUKi) ve Hastane Anksiyete ve Depresyon Ölçeği (HAD) kullanıldı.

\section{Veri toplama formları}

- Hasta tanıtım formu: Araştırmacı tarafından hazırlanan anket formu hasta sosyo demografik özelliklerini ve sağlık-hastalık ile ilgili özellikleri sorgulayan 11 ifadeden oluşmaktadır.

- Pittspurg Uyku Kalitesi Indeksi: Son bir ay içerisindeki uyku kalitesi ve uyku bozukluğunun tipi ve şiddeti konusunda bilgi veren bir ölçektir. Ölçeğin Türkçe geçerlilik ve güvenirliğini Ağargün ve arkadaşları yapmıştır. Ölçek, toplamda 24 ifadeden oluşmakta, bunun 19 tanesi kişi tarafından, 5 tanesi yatak arkadașı tarafından cevaplanmaktadır. Yatak arkadaşı tarafından verilen cevaplar değerlendirmeye alınmamaktadır. Öznel uyku kalitesi, uyku latensi, uyku süresi, alışımış uyku etkinliği, uyku bozukluğu, uyku ilacı kullanımı, gündüz işlev bozukluğu olmak üzere 7 alt boyutu vardır. Ölçekteki ifadeler 0-3 arası puan almakta, toplam PUKi puanı ise 0-21 arasında değer alır. Tüm alt boyutların toplamı toplam PUKI puanını verir. Toplam puanı 5 ve üstü olanların uyku kalitesi "kötü" olarak kabul edilmektedir (22).

- Hastane Anksiyete ve Depresyon Ölçeği: Bu ölçek 1983 yılında Zigmond ve Snaith tarafından geliştirilmiştir. Aydemir ve arkadaşları Türkçe geçerlik ve güvenirliğini 1997 yılında yapmıştır. Ölçek dörtlü likert tipte olup 14 ifadeden oluşmaktadır. Ifadelerden yedi tanesi anksiyete (HAD-A), yedi tanesi depresyon (HAD-D) alt boyutuna aittir. Anksiyete alt boyutu için kesme puanı 10 olup, depresyon için 7'dir. Bu puanların üzerinde değer alanlar risk altında kabul edilir. Ölçeğin amacı tanı koymak olmayıp, bedensel hastalığı bulunan bireylerde anksiyete ve depresyonu kısa zamanda tarayarak risk gruplarını belirlemektir (23).

\section{Verilerin değerlendirilmesi}

Araştırmadan elde edilen veriler istatistik programında değerlendirildi. Verilerin istatistiksel analizinde tanımlayıcı istatistiklerden sayı, yüzde ve ortalama analizleri kullanıldı. Ölçeklerin puanları arasındaki ilişkinin saptanması için korelasyon analizi kullanıldı. Aynı zamanda PUKi kesme puan dağılımları ile HAD ölçeği arasındaki fark için bağımsız gruplarda t-testi kullanıldı.

\section{Araştırmanın etik yönü}

Araştırmaya başlangıç öncesinde hastanenin ilgili bölümünden yazılı izin ve ilgili Üniversitenin Sağlık Bilimleri
Bilimsel Araştırma ve Yayın Etiği Kurulundan etik onay (No. 2015/10-5) alındı. Araştırmadaki katılımcılara çalışma hakkında bilgi verilip, elde edilen verilerin gizli tutulacağı, araştırmaya katılımın gönüllü olacağı açıklandıktan sonra sözel izinleri alındı. Bu araştırma Helsinki Deklarasyonu'nda belirtilen ilkelere uyularak yürütüldü.

\section{Bulgular}

Araştırmaya katılan hastaların \%59.7'sinin erkek, \%84.7'sinin 55 yaş ve üstü, \%88.2'sinin evli, \%51.4'ünün ilköğretim mezunu olduğu, \%58.3'ünün herhangi bir işte çalıştığı ve \%53.5'inin gelir durumunun orta seviyede olduğu, \%48.6'sının yaşamının çoğunu ilde geçirdiği tespit edildi. Aynı zamanda hastaların \%59.7'sinin hastalık süresinin altı yıl ve üstü olduğu, \%81.9'unun evde solunum desteği için cihaz kullandığı, \%57.6'sının ek kronik hastalığa sahip olduğu, \%43.1'inin sigara kullanmadığı saptandı (Tablo 1).

Tablo 1. Hastaların bireysel özelliklerine göre dağılımları (n: 144)

\begin{tabular}{|c|c|c|}
\hline Özellikler & $S$ & $\%$ \\
\hline $\begin{array}{l}\text { Cinsiyet } \\
\text { Kadın } \\
\text { Erkek }\end{array}$ & $\begin{array}{l}58 \\
86\end{array}$ & $\begin{array}{l}40,3 \\
59,7\end{array}$ \\
\hline $\begin{array}{l}\text { Yaş } \\
55 \text { yaş altı } \\
55 \text { yaş ve üstü }\end{array}$ & $\begin{array}{c}22 \\
122\end{array}$ & $\begin{array}{l}15,3 \\
84,7\end{array}$ \\
\hline $\begin{array}{l}\text { Medeni durum } \\
\text { Evli } \\
\text { Bekar }\end{array}$ & $\begin{array}{c}127 \\
17\end{array}$ & $\begin{array}{l}88,2 \\
11,8\end{array}$ \\
\hline $\begin{array}{l}\text { Eğitim düzeyi } \\
\text { Okur-yazar değil } \\
\text { Illköğretim }\end{array}$ & $\begin{array}{l}70 \\
74\end{array}$ & $\begin{array}{l}48,6 \\
51,4\end{array}$ \\
\hline $\begin{array}{l}\text { Çalışma durumu } \\
\text { Çalışıyor } \\
\text { Çalışmıyor }\end{array}$ & $\begin{array}{l}84 \\
60\end{array}$ & $\begin{array}{l}58,3 \\
41,7\end{array}$ \\
\hline $\begin{array}{l}\text { Gelir durumu } \\
\text { Gelir gidere eşit } \\
\text { Gelir gidere göre az }\end{array}$ & $\begin{array}{l}77 \\
67\end{array}$ & $\begin{array}{l}53,5 \\
46,5\end{array}$ \\
\hline $\begin{array}{l}\text { Yaşamın geçtiği yer } \\
\text { Köy } \\
\text { İlçe } \\
\text { il }\end{array}$ & $\begin{array}{l}56 \\
18 \\
70\end{array}$ & $\begin{array}{l}38,9 \\
12,5 \\
48,6\end{array}$ \\
\hline $\begin{array}{l}\text { Hastalık süresi } \\
1 \text { yıl ve altı } \\
2-5 \text { yıl } \\
6 \text { ve üzeri }\end{array}$ & $\begin{array}{l}20 \\
38 \\
86\end{array}$ & $\begin{array}{l}13,9 \\
26,4 \\
59,7\end{array}$ \\
\hline $\begin{array}{l}\text { Cihaz kullanımı } \\
\text { Evet } \\
\text { Hayır }\end{array}$ & $\begin{array}{c}118 \\
26\end{array}$ & $\begin{array}{l}81,9 \\
18,1\end{array}$ \\
\hline $\begin{array}{l}\text { Kronik hastalık } \\
\text { Var } \\
\text { Yok }\end{array}$ & $\begin{array}{l}83 \\
61\end{array}$ & $\begin{array}{l}57,6 \\
42,4\end{array}$ \\
\hline $\begin{array}{l}\text { Sigara kullanımı } \\
\text { Evet } \\
\text { Bıraktım } \\
\text { Hayır }\end{array}$ & $\begin{array}{l}31 \\
51 \\
62\end{array}$ & $\begin{array}{l}21,5 \\
35,4 \\
43,1\end{array}$ \\
\hline
\end{tabular}


Hastalar PUKI alt boyutlarından öznel uyku kalitesinden $1.75 \pm 0.74$, uyku latensinden $1.81 \pm 1.02$, uyku süresinden $1.40 \pm 1.25$, alışılmış uyku etkinliğinden $1.06 \pm 1.19$, uyku bozukluğundan 1.85 \pm 0.57 , uyku ilacı kullanımından $0.36 \pm 0.90$, gündüz işlev bozukluğundan $0.75 \pm 0.98$ puan almıştır. Hastaların PUKi toplam puanı $9.01 \pm 4.14$ olup, \%77.8'inin uyku kalitesi puanı 5 ve üstü çıkmıştır (Tablo 2).

Tablo 2. Hastaların PUKi toplam ve alt bileşenlerinden aldıkları puan ortalamaları ve dağılımı (n: 144)

\begin{tabular}{lc} 
Uyku Kalitesi & Ortalama (SD) \\
\hline Öznel uyku kalitesi & $1,7500(0,74327)$ \\
Uyku latensi & $1,8194(1,02863)$ \\
Uyku süresi & $1,4028(1,25336)$ \\
Alışılmış uyku etkinliği & $1,0694(1,19236)$ \\
Uyku bozukluğu & $1,8542(0,57899)$ \\
Uyku ilacının kullanımı & $0,3681(0,90644)$ \\
Gündüz işlev bozukluğu & $0,7569(0,98412)$ \\
Toplam uyku kalitesi & $9,0139(4,14929)$ \\
Global PUki puanı & $\boldsymbol{n}(\%)$ \\
\hline 5 ve üzerinde & $112(77,8)$ \\
4 ve altı & $32(22,2)$
\end{tabular}

Tablo 3'te hastaların HAD ölçeği toplam ve alt boyut puan ortalamaları ile dağılımları verilmiştir. Hastaların HAD-A alt boyutundan 7.53 \pm 5.33 , HAD-D alt boyutundan $10.27 \pm 5.31$ puan alıp HAD toplam puanı $17.79 \pm 9.59$ 'dur. Hastaların \%75'i anksiyete yönünden bulgu vermezken, \%68.7'si depresyon yönünden bulgulara sahiptir.

Tablo 3. Hastaları HAD toplam ve alt bileşenlerinden aldıkları puan ortalamalarııın dağıımı (n: 144)

\begin{tabular}{lc} 
HAD & Ortalama (SD) \\
\hline Anksiyete & $7,5(5,3)$ \\
Depresyon & $10,2(5,3)$ \\
Toplam puan & $17,7(9,5)$ \\
Hastane anksiyete puanı & $\mathrm{n}(\%)$ \\
Anksiyete var & $36(25,0)$ \\
Anksiyete yok & $108(75,0)$ \\
Hastane depresyon puanı & \\
Depresyon var & \\
Depresyon yok & $99(68,7)$ \\
\end{tabular}

Hastaların PUKi toplam puan dağılımları ile HAD-A ve HAD-D puan ortalamalarının karşılaştırılması sonucu aradaki farkın istatistiksel olarak anlamlı olduğu $(p<0.001)$ saptandı. Uyku kalitesi kötü olanların anksiyete ve depresyon açısından risk altında olduğu belirlendi (Tablo 4).
Tablo 4. Hastaların PUKi toplam puanı dağlımı ile HAD alt boyut ve toplam puan ortalamalarının karşılaştıııması (n: 144)

\begin{tabular}{lcccc} 
& \multicolumn{2}{c}{ PUKi } & \multicolumn{2}{c}{$\begin{array}{c}\text { istatistiksel } \\
\text { analiz }\end{array}$} \\
\hline HAD & Toplam puan<5 & Toplam puan $\geq 5$ & $\boldsymbol{t}$ & $\boldsymbol{p}$ \\
\hline & $( \pm \mathrm{SS})$ & $\mathbf{( \pm S S )}$ & & \\
Anksiyete & $4,03 \pm 3,26$ & $8,53 \pm 5,39$ & $-4,488$ &, 000 \\
$\begin{array}{l}\text { Depresyon } \\
\text { HAD toplam } \\
\text { puan }\end{array}$ & $6,90 \pm 3,89$ & $11,23 \pm 5,28$ & $-4,301$ &, 000 \\
& $10,93 \pm 6,65$ & $19,75 \pm 9,42$ & $-4,944$ &, 000
\end{tabular}

Hastaların PUKI toplam puanı ile HAD toplam ve alt boyut puan ortalamaları arasında istatistiksel olarak anlamlı ilişki $(p<0.01)$ saptandı (Tablo 5).

Tablo 5. Hastaların PUKi ve HAD puan ortalamaları arasındaki ilişki (n:144)

\begin{tabular}{lccc} 
& Anksiyete & Depresyon & HAD toplam \\
\hline PUKi & $r$ & $r$ & $r$ \\
Toplam uyku kalitesi & $.416^{\star *}$ & $.505^{\star *}$ & $.512^{\star *}$ \\
\hline${ }^{* *}<0.01$ & & &
\end{tabular}

\section{Tartışma}

Araştırmamız sonucunda hastaların PUKI toplam puan ortalamasının $9.01 \pm 4.14$ olduğu ve alt boyutları arasından en yüksek puanı uyku bozukluğu alt boyutundan aldığı (1.85 \pm 0.57$)$ saptandı. Ayrıca hastaların \%77.8'inin ölçekten 5 ve üzeri puan aldığı görüldü (Tablo 2). PUKl'den 5 ve üzeri puan almak uyku kalitesinin kötü olduğunu göstermektedir. Araştırmamıza katılan hastaların uyku kalitelerinin kötü olduğu görülmektedir. Yapılan bir çalışmada $\mathrm{KOAH}$ hastalarının uyku kalitelerinin kötü olduğu saptanmıştır (18). Yapılan başka bir çalışmada da hastaların 2/3'ünde insomnia yaşadıkları bulunmuştur (24). Chen ve arkadaşları KOAH hastaları ile yaptıkları çalışmalarında hastaların \%43.69'unun kötü uyku kalitesi olduğunu bulmuş ve bu grubun PUKi puan ortalamalarını 10.00 \pm 3.46 olarak saptamıştır. Tüm hastaların PUKi puan ortalamasını da $5.90 \pm 4.35$ olarak saptamıştır (25). Başka bir çalışma sonucunda da hastaların \%77.7'sinin uyku kalitesinin kötü olduğu saptanmıştır (26). KOAH hastaları ile yapılan başka bir çalışmada ise \%90'ının uykusuzluktan şikayetçi olduğu belirtilmiştir (27). Bizim çalışmamızda yapılan çalışmalarla benzer sonuçlara ulaşmıştır. KOAH hastalarında uyku süresi kısalarak, uyku kaliteleri kötüleşebilmektedir (6).

Kronik obstruktif akciğer hastalarında anksiyete ve depresyon şikayetleri sıklıkla görülmektedir. Depresyon sağlıklı bireylere göre iki ila dört kat daha fazla görülmektedir. 
Anksiyete ve depresyon bireylerin öz bakımlarını ve yaşam şekillerini olumsuz etkiler. Aynı zamanda hastalıın sağlık statülerini, yatış sıklıklarını ve semptom kontrollerini direkt etkiler. Bu yüzden anksiyete ve depreyonun tespiti hayati önem taşır $(28,29)$. Depresyonun KOAH alevlenmeleri, hastaneye yatışlar ve mortaliteyle ilişkili olduğu bildirilmiştir (30). Araştırmamız sonucunda hastaların $\% 25$ 'inde anksiyete varken \%75'inde olmadığı, \%68.7'sinde depresyonu varken \%31.3'ünde olmadığı saptandı (Tablo 3). Afşar ve arkadaşları yaptıkları çalışmalarında hastaların \%68'inin depresyon bulguları varken \%32'sinde olmadığını, \%44'ünde anksiyete bulguları varken \%56'sında olmadığını saptamıştır (3). Yapılan başka bir çalışmada hastaların anksiyeteleri yüksek bulunmuş, anksiyetesi olan hastalarda depresyon olduğu saptanmıştır (14). Literatürde yapılan çalışmalarda KOAH hastalarında depresyon görülme sıklığının \%11-\%40 arasında değiştiği görülmüştür. Ancak depresyon tanısı koymanın zor olduğu, çünkü semptomlarının KOAH'ın kendi semptomlarıyla karışabileceği belirtilmiştir. Bu yüzden hasta hikayesi ve fizik muayenenin önemli olduğu söylenmiş̧ir. Anksiyete ve depresyonun diğer kronik hastalıklara göre KOAH'da daha fazla görüldüğü belirtilmiştir $(31,32)$. Bir çalışmanın sonucunda anksiyete ve depresyonun KOAH hastalarında sosyal hayat ve fiziksel aktiviteyi olumsuz etkilediği bulunmuştur (33). Başka bir çalışmada da hastaların taburculuktan sonra yüksek düzeyde anksiyete ve depresyon yaşadıkları saptanmıştır (7). Yapılan başka çalışma sonuçlarında hastaların depresyon oranlarının yüksek olduğu belirtilmiştir $(17,34,35)$. Bizim araştırma sonucumuzda literatürle paralellik göstermektedir.

Araştırmamızda hastaların HAD anksiyete ve deporesyon puan ortalamaları ile PUKI puan ortalaması arasında pozitif yönde anlamlı ilişki olduğu saptandı (Tablo 5). Bu da hastaların anksiyete ve depresyon düzeyleri yüksek olunca uyku kalitelerinin de kötü olduğunu göstermektedir. Aynı zamanda araştırmamızda PUKI puan ortalaması dağıımı ile anksiyete ve depresyon arasındaki farkın istatistiksel olarak anlamlı olduğu $(p<0.001)$ tespit edildi. Uyku kalitesi kötü olanların anksiyete ve depresyon puan ortalamalarının daha yüksek olduğu saptandı (Tablo 4). Bu sonuca bakarak kötü uyku kalitesinin hastalarda anksiyete ve depresyon gibi durumlara neden olabileceği söylenebilir. Yapılan literatür taraması sonucu diğer çalışma sonuçlarının da bizim sonuçlarımızla paralellik gösterdiği görülmüştür. Literatürde KOAH hastalarının \%48.1'inin insomnia yaşadıkları, anksiyete ve depreyon şikayetlerinin sağlıklı insanlara göre üç kat daha fazla olduğu saptanmıştır. Hastaların depresyonda olanlarının \%90'ında, anksiyetesi olanların da \%59.7'sinde insomnia olduğu saptanmıştır. Hem anksiyetesi olan hem de olmayan KOAH hastalarının uyku kalitelerinin kötü olduğu saptanmıştır. Bu hastalarda uyku kalitesinin kötü etkilenebileceği, bunun içinde önlemler alınması gerektiği belirtilmiştir $(14,32)$. Lee ve arkadaşları uykusuzluğun KOAH'da sıklıkla görülen üçüncü semptom olduğunu belirtmiş ve yaptıkları çalışmalarında uykusuzluğun depresyona neden olduğunu saptamıştır (36). Yapılan başka bir çalışmada HAD toplam puan ile uykusuzluk arasında anlamlı ilişki olduğu saptanmıştır. Hastaların yaşadıkları psikolojik sorunların, kötü uyku kalitesine neden olduğu görülmüştür (24). Eslaminejed ve arkadaşları yürüttükleri çalışmalarında uyku kalitesi ile anksiyete ve depresyon arasında anlamlı ilişki olduğunu saptamış; uyku kalitesi, anksiyete ve depresyona dikkat edilmezse hastaların tedavi süreçlerinin bundan olumsuz etkileneceğini belirtmişlerdir (37).

\section{Sonuç ve öneriler}

Araştırmamız sonucunda KOAH hastalarının uyku kalitelerinin kötü olduğu, hastaların çoğunun depresyon şikayeti yaşadığı, uyku kaliteleri kötü olanların anksiyete ve depresyon yaşadıkları saptandı. KOAH ağır semptomların görülebileceği bir hastalıktır. Diğer kronik hastalıklarda olduğu gibi KOAH'da da ruh sağlığı oldukça önemlidir. Diğer tüm hastalıklara göre aksiyete ve depresyon KOAH'da daha fazla görülür. Aynı zamanda uyku problemleri de oldukça sık görülmektedir. Bu çalışma sonucunda uyku ile anksiyete ve depresyon arasında kuvvetli bir ilişki olduğu ortaya kondu. Bu durumda hastalara destekleyici bir psikolojik yardım ile uygun farmakolojik ve nonfarmakolojik yöntemlerin kullanıldığı bir yaklaşım gerekmektedir. Bu konuda hemşirelere önemli görevler düşmektedir. Bu konuda uzmanlaşmış hemşirelerle hastalara uygun bakım programlarının düzenlenmesi, uygun eğitimlerin hem hasta hem de yakınlarına verilmesi önerilebilir. 


\section{Kaynaklar}

1. Benzo RP, Abascal-bolado B, Dulohery MM. Patient Education and Counseling Self-management and quality of life in chronic obstructive pulmonary disease (COPD): The mediating effects of positive affect. Patient Educ Couns. 2016;99:617-23. [CrossRef]

2. Al-shair K, Dockry R, Mallia-milanes B, Kolsum U, Singh D, Vestbo J. Depression and its relationship with poor exercise capacity, BODE index and muscle wasting in COPD. 2009;1572-9.

3. Afşar BB, Yalçınsoy M, Yakar Hi, Bilgin S, Akkaya E. K ronik Obstrüktif Akciğer Hastalığı olan bireylerin yeti yitimi, anksiyete ve depresyon yönünden değerlend irilmesi (Evaluation of individuals with Chronic Obstructive Pulmonary Disease in terms of disability, anxiety and depression). Cumhur Med J. 2012;34:260-7.

4. Zamzam MA, Azab NY, Wahsh RA El, Ragab AZ, Allam EM. Quality of life in COPD patients. Egypt J Chest Dis Tuberc. 2013;61:281-9. [CrossRef]

5. Tel H, Demirkol D, Kara S, Aydın D. KOAH COPD KOAH ' I Hastaların Bakım Vericilerinde Bakım Yükü ve Yaşam Kalitesi (Care Burden and Quality of Life Among the Caregivers of Patients with COPD). Turk Toraks Derg. 2012;13:87-92.

6. Stege G, Vos PJE, Elshout FJJ Van Den, Dekhuijzen PNR, Ven MJT Van De, Heijdra YF. Sleep, hypnotics and chronic obstructive pulmonary disease. Respir Med. 2008;102:801-14.

7. Gudmundsson G, Gislason T, Janson C, Lindberg E, Suppli C, Brøndum $\mathrm{E}$, et al. Depression, anxiety and health status after hospitalisation for COPD: A multicentre study in the Nordic countries. 2006;87-93.

8. Başyiğit ì. Koah tanimi ve klinik özellikleri. TTD Toraks Cerrahisi Bülteni. 2010;1:102-4.

9. Kayhan S, Çınarka H, Köksal N. Kronik Obstrüktif Akciğer Hastalarının Perioperatif Değerlendirilmesi (Perioperative Evaluation of COPD Patients). Güncel Göğüs Hast Serisi. 2013;1:136-42.

10. Savaş HS, Günen H, Mutlu L cem, Gülbaş G. Kronik Obstrüktif Akciğer Hastalığında Alevlenme Nedenleri. Solunum Hast. 2006;17:8-12.

11. Ince Di, Savcı S, Çöplü L, Arıkan H. Kronik Obstrüktif Akciğer Hastalarında Günlük Yaflam Aktivitelerinin Değerlendirilmesi. Toraks Derg. 2005;6:31-6.

12. Mikkelsen RL, Middelboe T, Pisinger C, Mikkelsen RIEL, Middelboe $\mathrm{T}$, Pisinger $\mathrm{C}$. Anxiety and depression in patients with chronic obstructive pulmonary disease (COPD). A review Anxiety and depression in patients with chronic obstructive pulmonary disease (COPD). A review. 2017;9488(August).

13. Çil A, Olgun N. KOAH (Kronik obstruktif akciğer hastalığı)'ın pulmoner rehabilitasyon ile yönetimi. Ege Üniversitesi Hemşirelik Yüksek Okulu Derg. 2005;21:103-13.

14. Suh S, Ellis RJ, Sollers JJ, Thayer JF, Yang H, Emery CF. The effect of anxiety on heart rate variability, depression, and sleep in Chronic Obstructive Pulmonary Disease. J Psychosom Res. 2013;74:407-13. [CrossRef]

15. Pirraglia PA, Casserly B, Velasco R, Borgia ML, Nici L. Association of change in depression and anxiety symptoms with functional outcomes in pulmonary rehabilitation patients. J Psychosom Res. 2011;71:45-9. [CrossRef]

16. Crockett AJ, Cranston J, JR M, JH A. The Impact of Anxiety, Depression and Living alone in Chronic Obstructive Pulmonary Disease. Qual Life Res. 2016;11:309-16.

17. Marco F Di, Verga M, Reggente M, Casanova FM, Santus P, Blasi F, et al. Anxiety and depression in COPD patients: The roles of gender and disease severity. Respir Med. 2006;100:1767-74.

18. Saaresranta T, Irjala K, Aittokallio T, Polo O. Sleep quality, daytime sleepiness and fasting insulin levels in women with chronic obstructive pulmonary disease. 2005;856-63.
19. Bülbül Y. Kronik Obstrüktif Akciğer Hastalığında Uyku Sorunları (Sleep disturbances in chronic obstructive pulmonary disease). Güncel Göğüs Hast Serisi. 2013;1:80-5.

20. Öztürk Ö. Kronik Obstrüktif Akciğer Hastalığı ve Uyku (COPD and Sleep). Solunum. 2011;13:67-77.

21. Society TT. Kronik Obstrüktif Akciğer Hastalığı. Vol. 11. 2010.

22. Ağargun $M$, Kara $H$, Anlar O. Pittsburgh uyku kalitesiindeksinin geçerliği ve güvenirliği. Türk Psikiyatr Derg. 1996;7:107-15.

23. Aydemir Ö, Güvenir T, Küey L, Kültür S. Hastane anksiyete ve depresyon ölçeği Türkçe formunun geçerlilik ve güvenilirlik çalışması. Türk Psikiyatr Derg. 1997;8:280-7.

24. Hynninen MJ, Pallesen S, Hardie J, Eagan TML, Bjorvatn B, Bakke P, et al. Insomnia symptoms, objectively measured sleep, and disease severity in chronic obstructive pulmonary disease outpatients. Sleep Med. 2013;14:1328-33. [CrossRef]

25. Chen R, Tian J, Zhou L, Chen X, Yan H, Zeng B. The relationship between sleep quality and functional exercise capacity in COPD. 2015.

26. Scharf S, Maimon N, Simon-Tuval T, Bernhard-Scharf B, Reuveni H, Tarasik A. Sleep quality predicts quality of life in chronic obstructive pulmonary disease. Int J Chron Obstruct Pulmon Dis. 2011;1:1-12.

27. De S. Subjective assessment of quality of sleep in chronic obstructive pulmonary disease patient and its relationship with associated depression. 2012;29:332-6.

28. Elassal G, Elsheikh M, Gawad A, Zeid A. Assessment of depression and anxiety symptoms in chronic obstructive pulmonary disease patients: A case - control study. Egypt J Chest Dis Tuberc. 2014;63:575-82. [CrossRef]

29. Disler RT, Gallagher RD, Davidson PM. International Journal of Nursing Studies Factors influencing self-management in chronic obstructive pulmonary disease: An integrative review §. Int J Nurs Stud. 2012;49:230-42. [CrossRef]

30. Laforest L, Roche N, Devouassoux G, Belhassen M, Chouaid C, Ginoux $M$, et al. Frequency of comorbidities in chronic obstructive pulmonary disease, and impact on all-cause mortality: A populationbased cohort study. Respir Med. 2016;117:33-9. [CrossRef]

31. Kendrová L, Kuriplachová G, Miriam I, Nechvátal P, Miku W, Taká P. ScienceDirect Review article Assessment of depression in patients with chronic obstructive pulmonary disease. 2014;6:6-11.

32. Ohayon MM. Chronic Obstructive Pulmonary Disease and its association with sleep and mental disorders in the general population. J Psychiatr Res. 2014;54:79-84. [CrossRef]

33. Willgoss TG, Yohannes AM, Goldbart J, Fatoye F. "Everything was spiraling out of control": Experiences of anxiety in people with chronic obstructive pulmonary disease. Hear Lung J Acute Crit Care. 2012;41:562-71. [CrossRef]

34. Miravitlles M, Molina J, Quintano J, Campuzano A, Perez J, Roncero C. ScienceDirect Factors associated with depression and severe depression in patients with COPD'n Pe. Respir Med. 2014;108:1615-25.

35. Cramm JM, Nieboer AP. Patient Education and Counseling Selfmanagement abilities, physical health and depressive symptoms among patients with cardiovascular diseases, chronic obstructive pulmonary disease, and diabetes. Patient Educ Couns. 2012;87:4115. [CrossRef]

36. Lee H. Depression and Sleep Disturbance in Patients with Chronic Obstructive Pulmonary Disease. Geriatr Nurs (Minneap). 2010;32:408-17. [CrossRef]

37. Eslaminejad A, Safa M, Boroujerdi G, Hajizadeh F, Foroush MP. Relationship between sleep quality and mental health according to demographics of 850 patients with chronic obstructive pulmonary disease. 2017. 